\title{
LOW-ALTITUDE LONG-ENDURANCE SOLAR UNMANNED PLANE FOR FOREST FIRE PREVENTION: APPLICATION TO THE NATURAL PARK OF SERRA DO XURES (SPAIN)
}

\author{
H. González-Jorge ${ }^{\text {a }}$, M. Bueno a, J. Martínez-Sánchez ${ }^{\text {a }}$, P. Arias ${ }^{\text {a }}$ \\ ${ }^{a}$ CINAE, Galician Aerospace Centre, University of Vigo, Spain (higiniog, mbueno, joaquin.martinez, parias)@uvigo.es
}

\section{Commission VI, WG VI/4}

KEY WORDS: Unmanned aerial systems, remote sensing, low-altitude long-endurance, fire prevention

\begin{abstract}
:
Unamnned aerial systems (UAS) show great potential in operations related to surveillance. These systems can be successfully applied to the prevention of forest fires, especially those caused by human intervention. The present works focuses on a study of the operational possibilities of the unmanned system "AtlantikSolar" developed by the ETH Zurich for the prevention of forest fires in the Spanish natural park of Serra do Xurés, an area of 20,920 ha with height variations between $300 \mathrm{~m}$ and 1,500 m.

The operation evaluation of AtlantikSolar is based on the use of Flir Tau 2 LWIR camera as imaging payload which could detect illegal activities in the forest, such as bonfires, uncontrolled burning or pyromaniacs. Flight surveillance is planned for an altitude of $100 \mathrm{~m}$ to obey the legal limit of the Spanish UAS regulation. This altitude produces a swath width of $346.4 \mathrm{~m}$ and pixel resolution between 1.5 and 1.8 pixels/m. Operation is planned to adapt altitude to the change on the topography and obtain a constant ground resolution. Operational speed is selected to $52 \mathrm{~km} / \mathrm{h}$. The UAS trajectory is adapted to the limits of the natural park and the border between Spain and Portugal. Matlab code is developed for mission planning. The complete surveillance of the natural park requires a total time of 15.6 hours for a distance of $811.6 \mathrm{~km}$.
\end{abstract}

\section{INTRODUCTION}

Galicia is region of Spain located in the northwest of the Iberian Peninsula. It comprises the provinces of A Coruña, Lugo, Ourense and Pontevedra. It is bordered by the Cantabrian Sea at the north, Atlantic Ocean at the west, regions of Asturias and Castilla y León at east and Portugal at south. It has a population around 2.7 million (year 2016) and a total area of $29,574 \mathrm{~km}^{2}$ with over $1,660 \mathrm{~km}$ of coastline. Galicia presents a great natural wealth that includes a large coast and leafy forests. Main Galician forests (Fragas do Eume, Corrubedo, O Invernadeiro, Serra da Enciña da Lastra, Serra do Xures e Monte Aloia) are protected by the regional government as natural parks. The six parks add up to a total of 38,000 ha. They are areas that have not undergone excessive transformation by man and therefore have not affected too much the landscape, ecosystem and the singularity of its flora and fauna.

The largest natural park of Galicia is called Serra do Xurés (Serra do Xurés webpage, 2017). It presents an area of 20,920 ha with heights from $300 \mathrm{~m}$ around the Limia River up to $1,556 \mathrm{~m}$ at A Nevosa. Its highlights are the landscapes of glacial origin, as well as the thermal springs and Roman remains from Vía Nova (Roman road number 18 that joined Bracara Augusta with Asturica Augusta). Figures 1 and 2 show situation and landscape of Serra do Xurés Natural Park.

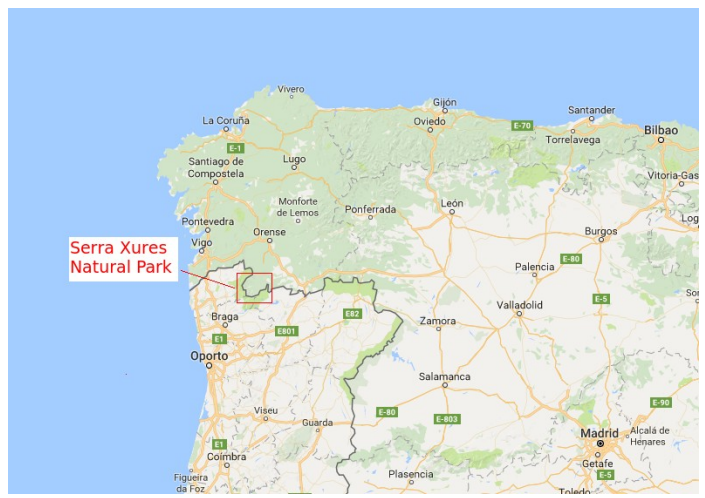

Figure 1. Situation of Serra Xures natural park.

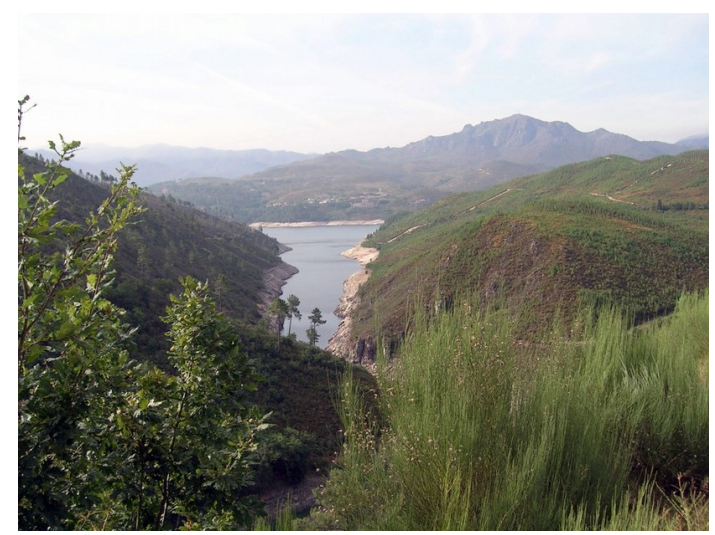

Figure 2. Landscape of Serra Xures natural park.

Forest fires are abundant in Galicia in summer months. Factors such as lack of rainfall, high temperatures (close to $40^{\circ} \mathrm{C}$ in inland areas away from the coast) and poor 
exploitation of the forest environment are linked. Serra do Xures is a clear example of this situation, both climatic and socioeconomic. At the present time its rural population is aged and in continuous diminution. As a result, there is a large amount of forest that is not clean for exploitation and that excess of vegetation shrub and scrubland causes fire spreads quickly. In addition, forest roads are often not clean, which also makes it difficult for firefighters to access.

All this problem forces the regional government of Galicia to invest a high budget in forest firefighting. The of figures between 2002 and 2012 exhibits a total budget of 959 million euros with an average of 86 million euros per year that was used for firefighting.

The highest cost of operation among the different sub-costs involved in the extincion of a forest fire lies in the use of different aircrafts. Heavy fixed-wing airtankers have an operating cost of aproximately 4,200 €/hour, while lighter ones show an approximate cost of $850 €$ /hour. Firefighting helicopters depict operation costs of $1,100 €$ /hour, both tankers (Figure 3) and brigade transport, while the coordination helicopters achieve 1,600 €/hour. Therefore, any reduction in the use of aerial firefighting systems would be appreciated (Vázquez, M. C.; 2014).

Unmanned aerial systems show great potential in the firefighting, especially in the surveillance tasks to avoid the beginning of the fire event and in the coordination during the firefighting procedure (Ollero, A., 2006; Casbeer, D. W., 2012; Merino, L., 2012; Watts, A. C., 2012).

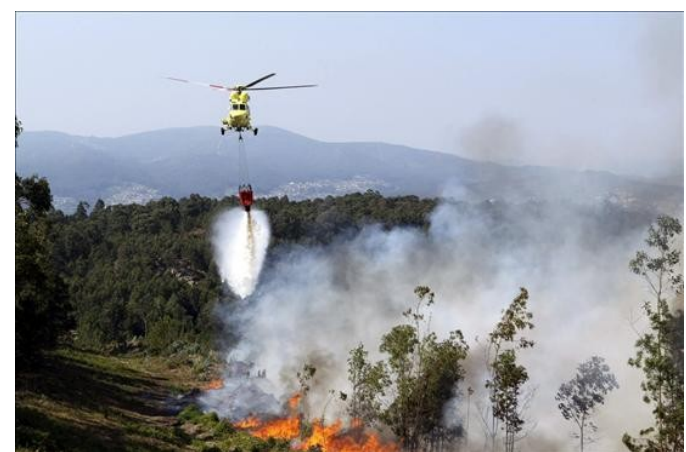

Figure 3. Example of fire extinction using a helicopter.

The regional government is making efforts in this regard through the AXEGA - Galician Emergeny Agency (AXEGA webpage, 2017), which includes an Unmanned Aerial Systems unit that can be deployed to provide support in this type of emergency actions. Their UAS include RGB and thermal imaging, although the limiting factor is that these systems show very short flight time (around 30 minutes) that greatly limit the capacity of the operation.

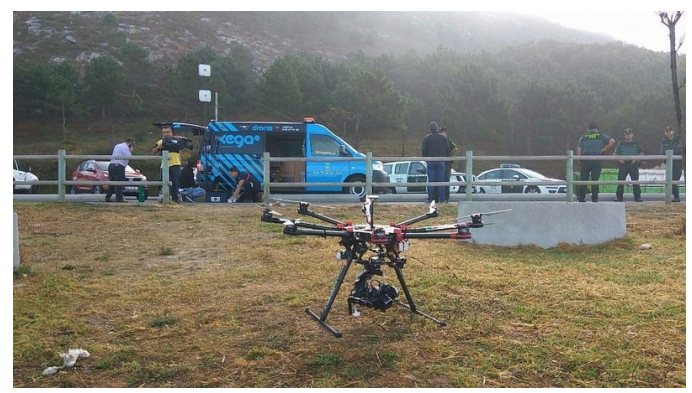

Figure 4. Example of AXEGA unmanned aerial system.
There are several options to increase the autonomy of the unmanned aerial systems. One is to use combustion engines (Figure 5), although it has the drawback of the high costs in purchasing, operation and maintenance. The combustion engine usually produce vibrations that need to be isolated from the gimbal of the cameras to obtain images of sufficient quality in the monitoring process.
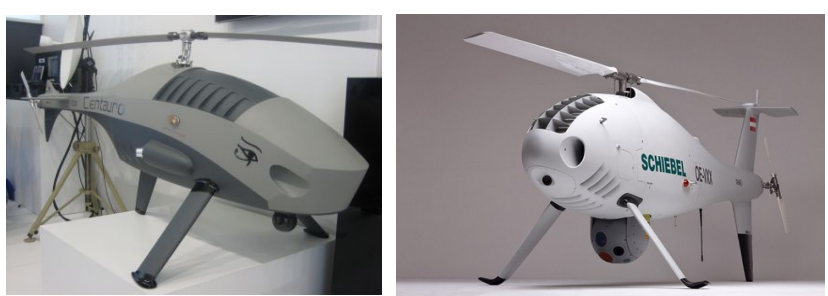

Figura 5. Examples of unmanned aerial systems based on combustion engines.

Other option is based on the use of solar panels assembled to the plane's wings to provide energy to the electric engines. Solar-electrically powered fixed-wing unmanned aerial systems provide significant increase in flight autonomy over purely-electrically or combustion-powered engines. A solarpowered UAS uses solar energy gathered during the day to operation. In any cases, even the stored energy may even be enough to keep the UAS flying during the night (Mehta, A.; 2012).

Solar planes can be divided into two main groups, highaltitude long-endurance (HALE) UAS, also called atmospheric satellites, and low-altitude long-endurance (LALE) applications. First group are configured as platforms to act as telecommunications relay. One typical example is the Zephyr system from Airbus. These systems are expensive and difficult to operate. On the other hand, LALE systems are cheaper, easy to manufacture and to operate. With a maximum take-off weight (MTOW) lower than $10 \mathrm{~kg}$ and a wing spam around 5-6 m they can fly around $1 \mathrm{~kg}$ payload. Some examples are the SkySailor (SkySailor webpage; 2017) or the AtlantikSolar (AtlantikSolar webpage; 2017) (Figure 6). The AtlantikSolar (Oettershagen, P., 2016) is a demonstrator solar UAS developed by the ETH Zurich.

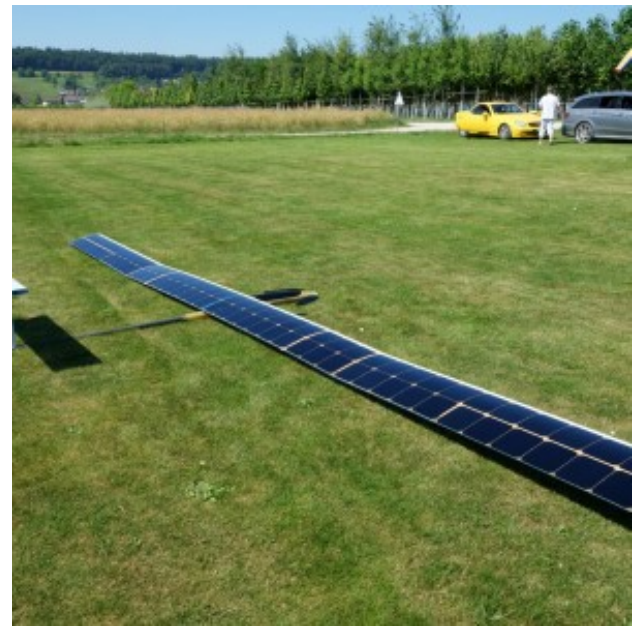

Figure 6. Image of AtlantikSolar UAS. 


\section{MATERIAL AND METHODS}

\subsection{AtlantikSolar UAS}

The Autonomous Systems Lab from ETH Zurich developed in 2008 the SkySailor, the first 3 m class solar UAS worldwide to demonstrate flights of more than a day only using solar power. The AtlantikSolar is a largely improved and upscaled aircraft based on Skysailor, which results in a new generation of $5 \mathrm{~m}$ wing span solar-powered UAS. It is also capable of performing continous flights up to 10 days. It combines efficient solar-cells with state-of-the-art Li-Ion batteries. It uses an autonomous control system developed also at ETH Zurich. Their main technical specifications are described in Table 1 and Figure 7 .

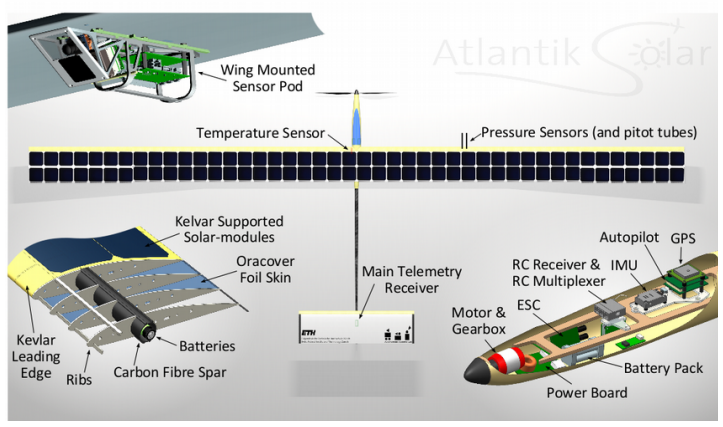

Figure 7. AtlantikSolar main subsystems.

Table 1. AtlantikSolar UAS. Technical specifications.

\begin{tabular}{|l|l|}
\hline Wing span & $5.6 \mathrm{~m}$ \\
\hline Mass & $6.9 \mathrm{~kg}$ \\
\hline Flight speed & $30-75 \mathrm{~km} / \mathrm{h}$ \\
\hline Structure & $\begin{array}{l}\text { Lightweight carbon fibre \& } \\
\text { kevlar structure }\end{array}$ \\
\hline Power system & $\begin{array}{l}1.4 \mathrm{~m}^{2} \text { solar panels with } 2.9 \\
\mathrm{~kg} \mathrm{Li-Ion} \text { batteries. }\end{array}$ \\
\hline Flight control & $\begin{array}{l}\text { Autonomous control system } \\
\text { with Global Navigation } \\
\text { Satellite System thermal }\end{array}$ \\
\hline Payload & $\begin{array}{l}\text { Digital HD-camera, timage } \\
\text { camera, live } \\
\text { transmission. Up to 1 kg. }\end{array}$ \\
\hline & \multicolumn{1}{|c|}{. } \\
\hline
\end{tabular}

The sensor POD includes a grayspace (Aptina MT9V034) camera with high dynamic range a long-wavelength infrared camera (FLIR Tau 2) for thermal imaging. Both are mounted with an oblique field of view, as well as a nadir facing RGB camera (uEye XS 2). An IMU from Analog Devices ADIS16448 is included to measure linear accelerations, angular velocities and the triaxial magnetic field. All the acquired data are sychronized and timestamped. The system also included an embedded computer Kontron COMe-mBT10 with an Intel Atom CPU (4 cores, $1.91 \mathrm{GHz}$ ). It is interfaced with the VI-sensor and the PX4 autopilot board of the UAS. The on-board Atom computer further communicates with the PX4 in order to receive all globe pose estimates and raw sensor data to transmit waypoints. The acquired data are onboard processed and transmitted to the ground control station using Wi-Fi in close ranges or Iridium satellite in long range. All elements of the POD are mounted on an aluminium frame to ensure rigid connection between the cameras and guarantee the calibration of the sensors. The on-board computer runs a standard Ubuntu Linux operating system, allowing quick adaptation to different kinds of missions.

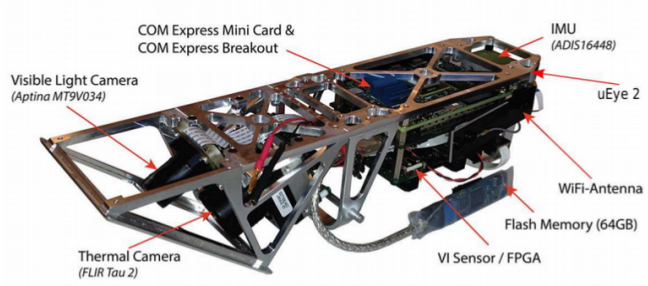

Figure 8. AtlantikSolar sensor POD.

\subsection{Flir Tau 2 camera system}

The study carried out is oriented to the early detection of fire sources or pyromaniacs. For this reason, the most appropriate image system for the AtlantikSolar POD seems to be the Flir Tau 2 thermal camera (Figure 9) (Flir Tau 2 webpage, 2017). It shows a resolution of $640 \times 512$ pixels with up to 30 frames per second. Using a $13 \mathrm{~mm}$ lens and a flight height of $100 \mathrm{~m}$, swath width is limited to $346.4 \mathrm{~m}$ and pixel resolution ranges between $1.8 \mathrm{pixel} / \mathrm{m}$ and $1.5 \mathrm{pixel} / \mathrm{m}$.

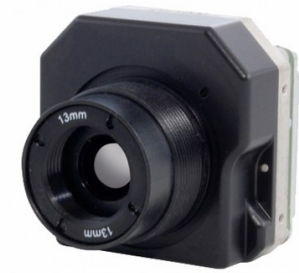

Figure 9. Flir Tau 2 camera with different lens options.

\subsection{Mission simulation}

First step for mission simulation consists on determination the geographical limits of the Serra do Xures natural park. For this purpose a shape layer is downloaded from the National Geographic Institute of Spain (Figure 10). The shape file uses point attributes, however spatial point density appears very low (blue points in figure). The border density is increased using linear fitting algorithm along the points. The new border is depicted with a red line.

Mission simulation is determined in base of AtlantikSolar thermal camera characteristics. The maximum swath of 346.4 $\mathrm{m}$ at $100 \mathrm{~m}$ distance to ground using the Flir Tau 2 camera provides the maximum distance between the UAS strips. In this work they are limited to $300 \mathrm{~m}$ to guarantee some overlapping between the consecutive routes. The routes are planned in North - South direction. They are limited to the border of the natural park in all the situations where this limitation optimizes the mission time. Route planning is shown as black lines in Figure 10. The height of the mission is 
adapted to the terrain to maintain it approximately constant and the consequent camera resolution. For this purpose, a digital terrain model (DTM) from the National Geographic Institute of Spain is used as input value for the route programming algorithm. DTM with $5 \mathrm{~m}$ pixel resolution is used for this purpose. All the mission simulation is automatized using Matlab software. QGIS software is used for visualization.

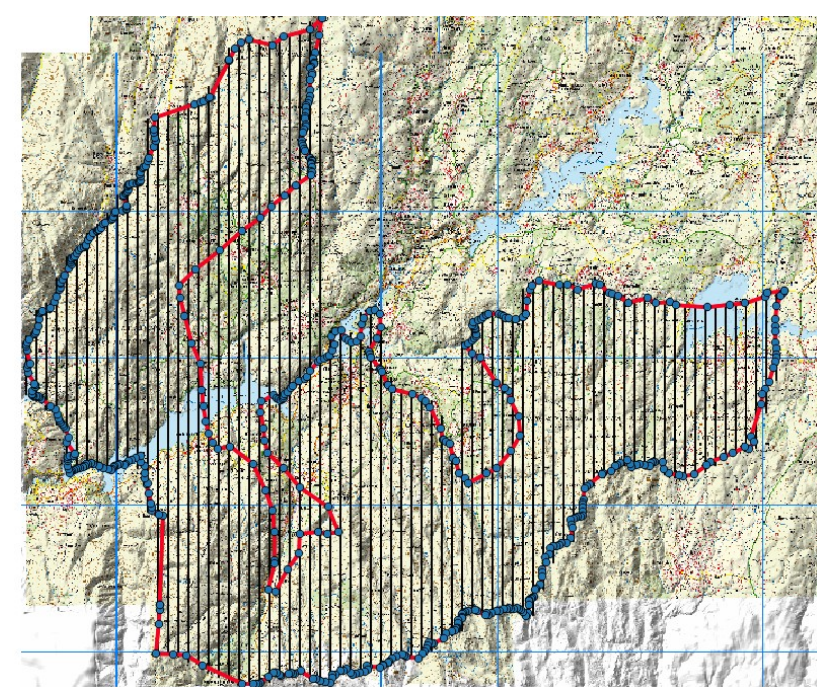

Figure 10. Serra do Xures natural park limits. Original shape points in blue and densified border in red. Mission route is exhibited with a black line.

\section{RESULTS AND DISCUSSION.}

Figure 11 shows the height change versus the horizontal distance of the mission route. It was evaluated taking into account a distance between the plane and the ground of $100 \mathrm{~m}$ and the variation of the digital elevation model. As can be observed, height changes from a minimum around $400 \mathrm{~m}$ to a maximum close to $1200 \mathrm{~m}$. It can be observed that the adaptation of the flight of the AtlantikSolar to the ground height is critical to keep the resolution of the cameras constant to $1.5-1.8 \mathrm{pixel} / \mathrm{m}$. On the contrary, if the mission is performed without ground distance control, the resolution could drop to $0.2 \mathrm{pixel} / \mathrm{m}$. This resolution appears extremely low to perform a good detection. Figure 12 depicts the resolution change in function of distance between UAS and ground.

Mission height is evaluated each kilometre. Total horizontal distance travelled is $811.3 \mathrm{~km}$. The time spent during the mission is 15.6 hours ( $52 \mathrm{~km} / \mathrm{h}$ horizontal speed). The light hours in the Spanish summer are over 14 hours. Thus, during the months of June, July, August and September the plane could fly during all the day preventing fires or supporting the firefighting operations if would necessary.

Figure 13 exhibits the pitch variation versus the horizontal distance of the mission route. It was calculated based on the relation between the height change in each mission step and the corresponding horizontal distance. Mission step is also evaluated to each one kilometre. More resolution can be easily implemented although this value seems adequate to present a clear graph in this manuscript. An extremely high spatial frequency will affect negatively to that.
Pitch angle ranges between $-6^{\circ}$ (descent) to $7^{\circ}$ (climb). In both cases it seems that the angles are achievable by the AtlantikSolar.

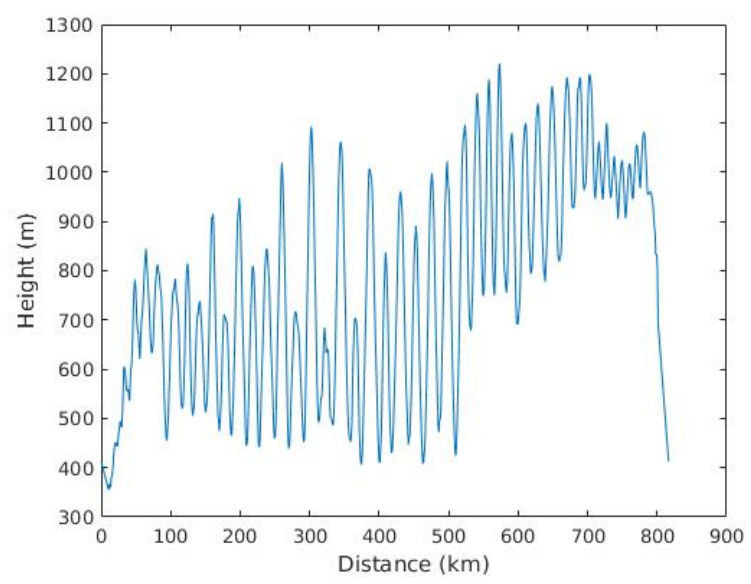

Figure 11. Height variation versus mission distance.

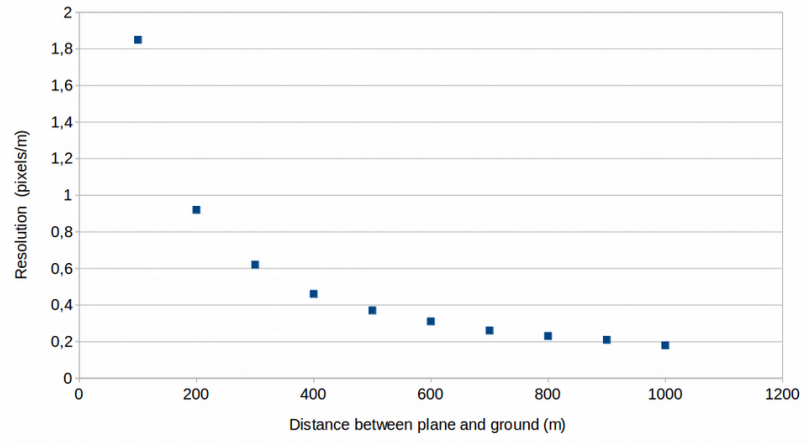

Figure 12. Resolution change in function of distance between plane and ground.

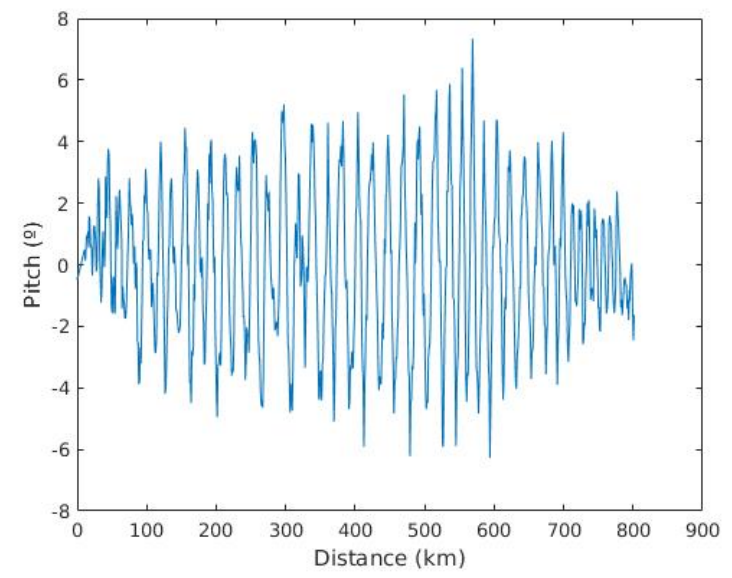

Figure 13. Pitch change versus mission distance.

\section{CONCLUSIONS.}

An operational simulation of the applicability of solar UAS to the surveillance of natural parks and prevent forest fires is done. The AtlantikSolar UAS and the natural park of Serra do Xures in Spain is used for the simulation. The AtlantikSolar 
can operate in a continuous form during cycles higher than 24 h.

Operational height over ground is keep constant to $100 \mathrm{~m}$ during all the survey to maintain the same optical resolution in the sensors. Ground level changes between $400 \mathrm{~m}$ and 1200 $\mathrm{m}$. The study is focused in the thermal camera Flir Tau 2 assembly to the AtlantikSolar. It provides a resolution between $1.5-1.8$ pixels $/ \mathrm{m}$. Camera swath is $346.4 \mathrm{~m}$ with a $13 \mathrm{~mm}$ lens. A constant flight height would produce changes in resolution from 1.8 pixels $/ \mathrm{m}$ to $0.2 \mathrm{pixel} / \mathrm{m}$, so the adaptation to the ground seems to be a good operational response to this type of terrains. In addition. The maximum climb and descend pitch angles to the plane are $-6^{\circ}$ and $7^{\circ}$, respectively.

Mission horizontal speed is estimated to $52 \mathrm{~km} / \mathrm{h}$. The UAS needs 15.6 hours to travel the $811.3 \mathrm{~km}$ necessary to cover all the natural park. In summer months between June and September it will be enough to kept the system flying during the day and avoiding the most problematic night cycles that force it to the physical limit.

Future trends can study other operational characteristics of the mission as the optimization of route planning, inserting random routes, and performance of different fixed-wing aircrafts to adapt to the terrain variations.

\section{ACKNOWLEDGEMENTS}

Authors want to give thanks to Spanish Government (Grant No: TIN2016-77158-C4-1-R) and Xunta de Galicia (Exp No: ED431C 2016)..

\section{REFERENCES}

AtlantikSolar webpage, 2017:

http://www.atlantiksolar.ethz.ch/

AXEGA webpage, 2017: http://www.axega112.org/

Casbeer, D. W, 2006. Cooperative forest fire surveillance using a team of small unmanned air vehicles. International Journal of Systems Science, 37(6), pp. $351-360$.

Flir Tau 2 webpage, 2017: https://www.flircameras.com/flirtau-2-thermal

Mehta, A., 2012. Solar aircraft: Future need. International Journal of Advanced Engineering Technology, III(I), pp. 43 48.

Merino, L., 2012. An unmanned aircraft system for automatic forest fire monitoring and measurement. Journal of Intelligent \& Robotic Systems, 65(1), pp. 533 - 548.

Oettershagen, P., 2016. Long-Endurance sensing and mapping using a hand-launchable solar-powered UAV, Field and Service Robotics, IV, pp. 441 - 454.

Ollero, A., 2006. Unmanned aerial vehicles as tools for forestfire fighting, International Conference on Forest Fire Research, pp. 1 - 11.

Serra do Xures webpage, 2017: http://www.turismo.gal/quevisitar/espazos-naturais/parques-naturais/parque-naturalbaixa-limia-serra-do-xures
SkySailor webpage, 2017: http://www.sky-sailor.ethz.ch/

Vázquez, M. C., 2014. Estimación de los costes de las operaciones de extinción de los incendios forestales: Estudio de caso en el distrito forestal de A Limia. Revista Gallega de Economía, 23(1), pp. 99-113.

Watts, A. C., 2012. Unmanned aircraft systems in remote sensing and scientific research: Classification and consideration of use. Remote Sensing, 4(6), pp. 1671 - 1692. 